\title{
Anthropometric indices of primary school children from different socio-economic classes in Owerri municipal
}

\author{
Obiakor- Okeke, P. N. \\ Faculty of Health Sciences, Department of Nutrition and Dietetics, Imo State University, PMB 2000, Owerri, Imo State Nigeria
}

Email address:

ngoziobiakor2001@yahoo.com

\section{To cite this article:}

Obiakor- Okeke, P. N.. Anthropometric Indices of Primary School Children from Different Socio-Economic Classes in Owerri Municipal. European Journal of Preventive Medicine. Vol. 2, No. 5, 2014, pp. 63-68. doi: 10.11648/j.ejpm.20140205.11

\begin{abstract}
This study was carried out to assess anthropometric measurement and growth pattern of primary school children from different socio-economic class in Owerri municipal. A total of three hundred and two (302) respondents comprising 132 males and 170 females from the selected primary school were used. A stratified multistage sampling technique was thus use to select one private school and one public school. A well structured and validated questionnaire was used to obtain the subject parents occupation, highest educational level and income level. Also, their weight and height were measured. Data collected were analysed using statistical package for social science (SPSS) version 13, chi-square, frequency, percentage and standard deviation was determined. The result showed that $40.1 \%$ of the subjects were stunted, $25.2 \%$ were underweight and $40.1 \%$ were wasted. It was also discovered that there was no significant difference $(\mathrm{P}>0.05)$ in the rate of stunting among the growth pattern of pupils based on different educational status of the parents, although stunting occurred more (48.9\%) among pupils whose parents had only primary education. Children their parents had tertiary education also had high record of stunting $(42.7 \%)$ while those that their parents had no formal education had recorded the least percentage of stunting $(23.1 \%)$. However, there were significant differences $(p<0.05)$ for wasting and underweight among the pupils whose parents' educational background differed. Parents with no formal education has a lowest proportion of children with wasting $(23.1 \%)$ than all other groups, while parents with tertiary education have the highest proportion of children with wasting (43.9\%) and pupils whose parents had only primary education recorded the most underweight $(33.3 \%)$. The occupation of parents significantly $(\mathrm{p}<0.05)$ affected the anthropometric indices of weight for age and weight for height of their children. Higher rates of stunting $45.8 \%$ and $51.4 \%$ were respectively observed among the children of civil servants and traders than farmers $(23.1 \%)$ and others $(32.5 \%)$. Also, wasting was highest among children of civil servants $(50.4 \%)$, followed by children of farmers $(38.5 \%)$ and then, children of traders $(37.1 \%)$. There was no significant difference $(\mathrm{p}>0.05)$ in the rate of stunting of growth pattern of pupils base on different income level of parents, although pupils whose parents income $<20,000$ who were stunted where more than other groups $(43.3 \%)$. It was concluded that nutrition education should be encouraged among the mothers to bring awareness of the benefits of hygiene conditions, nutrition knowledge as well as good child feeding practices.
\end{abstract}

Keywords: Anthropometric Indices, Primary School Children, Socio-Economic Class, Owerri Municipal

\section{Introduction}

The term growth can be defined as the natural increase in size resulting from the multiplication of the body cells ${ }^{[1]}$. Growth is generally reflected in the body size, height, weight and development. Growth and development are closely related, while but they are not identical. This means growth is increase in size, as development is increase in complexity. Growth can be accurately measured but the measurement of development is much more difficult.
Growth is associated with anthropometric indices such as weight, height, length, head circumference, arm circumference, chest circumference, hip circumference, waist circumference, abdominal circumference, skin fold thickness. Whereas development is associated with maturation in motor control such as crawling, sitting, toddling, walking, emotion maturation such as crying, fear, laughing etc., mental maturation and behavioural changes ${ }^{\text {[2] }}$. However, one cannot be considered in isolation from the other as they are affected by common factor. 
Growth pattern vary from species to species occurring in all living things but the rate of growth differs. Human being shows two periods of rapid growth. The first is in infancy (which is a continuation of the foetal growth period) and the second is at the time of puberty just before growth gradually stop. Babies lose weight in the first three days of life and regain their birth weight after 10days, thereafter; weight gain averages about $20 \mathrm{~g}$ per day for first five months of life and about $15 \mathrm{~g}$ per day for the remainder of the first year ${ }^{[3,4,5]}$.

Another period of rapid growth is from 6years to puberty age that is about 12 years. This period is characterized by slow but steady physical growth and differs among boys and girls and even among children of the same age. The difference is due to some ecological factors affecting their nutritional status especially socioeconomic factors $[3,4,5]$.

Growth is a remarkable process that transforms a microscopic embryo into a newborn baby approximately 20inches long, and eventually into an adult usually between 5 and 6 feet tall. Biomedical research has provided great insights into human growth, although much remains to be learned. Children grow taller because the cells throughout their body enlarge and then divide to form two cells. Then each of those cells enlarges and divides again ${ }^{[2]}$.

A child's height is primarily determined by the length of his or her bones, and thus children grow taller because their bones grow larger. The bones grow longer because they contain growth plates. These plates are thin layers of cartilage found near the ends of the bones. Cartilage is a firm, resilient material found in our ears and nose, as well as lining the ends of the bones at the joints. Children also have cartilage farther inside the bones, forming the growth plates. Within the growth plates, cells divide and enlarge, producing more cartilage, which is subsequently converted into bone. This process causes the bones to elongate ${ }^{[2]}$.

Growth basically is influenced by their main factors which is the genes that helps to direct the shaping of cells, hormones to control many chemical reactions within the cell and nutrients including water and oxygen supply raw materials for growth ${ }^{[6]}$. Nutrition generally is affected by some socio-economic factors such as income level, poverty, quality of diet, taboos and customs etc ${ }^{[3,4,5]}$. This means that the nutritional status of children can be influenced by the factors mentioned above inherent in the community they belong.

Many studies have shown differences in growth pattern among school age children (6-12years) in some geographical location and these studies indicate that school age children from lower socio-economic class were below standard, while those from upper socio-economic class compared favourably with standard ${ }^{[7]}$.

The question now is to find out the growth pattern of primary school children from different socio-economic class and the factors affecting their growth pattern if any.

Nutrition is very essential in the existence of life and as such plays a dominant role in growth. Studies have emphasized adequate nutrition in order to boost the nutritional status of children and help them achieve the maximum genetic potentials for their physical and mental development. In spite of the various measures aimed at improving the nutritional status of children, there are still problems which affect the nutritional status of children, thereby affecting their growth potential. These problems range from nutrient deficiency disease (under nutrition) to over nutrition ${ }^{[3,4,5]}$.

Studies of Nnanyelugo ${ }^{[8]}$ on the nutritional status of school age children in Imo State indicated evidence of stunted growth and underweight for age and height. Inadequate food intake stunts growth and has been shown repeatedly to reduce learning ability, memory and behaviour ${ }^{[5]}$. Children from low income parents suffer under nutrition in form of nutrient deficiency disease, since their parents cannot afford to provide adequate amount of foods. Nduba ${ }^{[7]}$ reported presence of deficiency disease in primary school age children in Imo State leading to underweight and low anthropometric measurement or indices. The nutritional deficiency disease reported by Nduba ${ }^{[7]}$ include; impaired mental development, impaired physical development and the late puberty growth spurt due to malnutrition which results from lack of knowledge of food values, food preparatory methods, prejudices against foods, ecological and agricultural limitations impairing production.

It was equally observed that in Nigeria, $31 \%$ of children under-five have been reported underweight, 16\% wasted and $34 \%$ stunted. Malnutrition is associated with increased morbidity. About $30-40 \%$ of deaths in pre-school age children in Nigeria are associated with malnutrition. In Nigeria Food Consumption and Nutrition Survey and Nigeria Demographic and Health Survey observed that in Nigeria, the rate of stunting among under-five children exceeds $40 \%$, wasting about $90 \%$ and underweight $25 \%$. At least $60 \%$ of children who die from different causes have malnutrition as an underlying cause ${ }^{[9]}$.

The primary purpose of this study is; to determine the Anthropometric indices of primary school children, to determine the growth pattern of primary school children in different socio-economic group and to determine the factors responsible for the different growth potentials that exists in children of the same socio-economic status.

This study will provide the health workers with specific information which can direct them to major areas of concern on the nutritional status of primary school children. Also Information obtained from the study will be of immense benefit to the individual child and the family, because it will provide a picture of the child's growth, his state of health in terms of nutrition and disease state. Hence, with this comprehensive picture, the parents of the child can be advice on appropriate routine care to be taken which will help promote adequate growth and health of the child. 


\section{Materials and Methods}

\subsection{The Study Area}

The study area was Owerri Municipal Council, Owerri is the capital of Imo State, Nigeria. The socio-economic status of the inhabitants of this area is highly a heterogeneous one with most parents being low income, some middle income and others high income earners. Most parents living in these local Government Areas are civil servants, public servants, traders, businessmen and women, teachers and farmers and artisans.

\subsection{Sample Selection}

A total number of 10 primary school (4 public and 6 private schools) were found in Owerri Municipal Council. A stratified multistage sampling technique was thus used to select one school each from the private (Foundation Nursery and Primary school) and public (Ikenegbu primary school), comprising 129 and 173 pupils respectively thus making a total sample size of 302 pupils.

\subsection{Data Collection}

The Anthropometry of the pupils was measured by the researcher, while other information on the questionnaire was filled by their parents on behalf of their children and finally was returned back to the researcher. The instruments and data collected are as follows;

\subsubsection{Questionnaire}

A validated questionnaire was used for the data collection. The questionnaire was structured to elicit information such as the age, sex, occupation of parents and the income level of the parents etc.

\subsubsection{Anthropometry}

Anthropometric measurements of weight, height and mid upper arm circumference were measured.

\subsubsection{Weight}

The actual weight was determined with a bathroom weighing scale. The weighing scale was checked and adjusted if need be to the zero mark before the subjects mounted the scale and their weight was recorded.

\subsubsection{Height}

Heights were measured with a vertical measuring rod calibrated in centimetres $(\mathrm{cm})$. The subject stood erect looking straight on a levelled surface with heels together and toes apart, without shoes. The moving head piece of the measuring rod was lowered to rest flat on the top of head and the reading was taken to the nearest centimetre.

\subsection{Data Analysis}

Nutritional parameters such as height-for-age (stunting), weight-for-age (underweight) and weight-for-height (wasting) were used to assess nutritional status of the children. This was interpreted by the Z-score classification system of World Health Organisation of child growth reference standard (2006).

The questionnaire were coded and keyed into the computer, analyzed using the statistical package for social science (SPSS) version 13 software. Descriptive statistics such as frequencies, percentages, mean and standard deviation as well as chi-square analysis were used to appraise the validity and reliability if the dependent variables such as weight-for-age, height-for-age and weight-for-age.

\subsection{Chi-Square}

$$
X^{2} F=\frac{(F o-F e)^{2}}{F e}
$$

$\mathrm{Fe}=$ Expected frequency in a given classification $\mathrm{Fo}=$ Observed frequency in a given classification Mean square deviation (MSD) method;

$$
S^{2} n F=\frac{\left(X^{2}\right)-\left(F X^{2}\right)}{n(n-1)}
$$

\section{Result}

\begin{tabular}{|c|c|c|}
\hline Variables & Frequency $(\mathbf{F})$ & Percentage (\%) \\
\hline \multicolumn{3}{|l|}{ Sex } \\
\hline Male & 132 & 43.7 \\
\hline Female & 170 & 56.3 \\
\hline \multicolumn{3}{|l|}{ Age (years) } \\
\hline $6-8$ & 92 & 30.5 \\
\hline $9-10$ & 98 & 32.5 \\
\hline $11-12$ & 112 & 37.0 \\
\hline \multicolumn{3}{|l|}{ Religion } \\
\hline Christian & 298 & 98.7 \\
\hline Muslims & 4 & 13 \\
\hline Others & - & - \\
\hline \multicolumn{3}{|l|}{ Family Type } \\
\hline Monogamous & 281 & 93.0 \\
\hline Polygamous & 21 & 7.0 \\
\hline \multicolumn{3}{|l|}{ Occupation of Parents } \\
\hline Civil servant & 131 & 43.4 \\
\hline Traders & 35 & 11.6 \\
\hline Farmers & 13 & 4.3 \\
\hline Others & 123 & 40.7 \\
\hline \multicolumn{3}{|l|}{ Parent's Educational } \\
\hline \multicolumn{3}{|l|}{ Level } \\
\hline Primary & 45 & 14.9 \\
\hline Secondary & 73 & 24.2 \\
\hline Tertiary & 171 & 56.6 \\
\hline No formal education & 13 & 4.3 \\
\hline \multicolumn{3}{|c|}{ Parent's Averge Monthly } \\
\hline \multicolumn{3}{|l|}{ Income } \\
\hline$<20,000$ & 90 & 29.8 \\
\hline $21,000-40,000$ & 184 & 60.9 \\
\hline$>40,000$ & 27 & 8.9 \\
\hline \multicolumn{3}{|l|}{ Residential Area } \\
\hline Urban & 193 & 63.9 \\
\hline Rural & 58 & 19.2 \\
\hline Semi urban & 51 & 16.9 \\
\hline
\end{tabular}

Table 1. Personal and Demographic Characteristics

**NOTE** 1.00 US Dollar $=160.00$ Naira. 
Table 1 showed that $56.3 \%$ of the samples population were females and 43.7 were males. Ages $11-12$ years were more $(37 \%)$ while $6-8$ years were the least in number $(30.5 \%)$. Majority $(98.7 \%)$ were of Christian religion and $13 \%$ were Muslims. Most (93\%) were from monogamous family. majority of their parents were Civil servants $(43.4 \%)$ while farmers were the least $(4.3 \%)$. The parent's were mostly educated: Tertiary $56.6 \%$, Secondary $24.2 \%$, primary $14.9 \%$ and only $4.3 \%$ did not acquire formal education. The majority of the parents receive income ranging from 21,000 - 40,000 naira monthly $(60.9 \%)$ while only $8.9 \%$ receive above 40,000 naira and $29.8 \%$ receive below 20,000 naira monthly. Most (63.9\%) live in the urban area.

Table 2. Dietary habits of the pupils

\begin{tabular}{lll}
\hline Variables & Frequency(F) & Percentage (\%) \\
\hline No. Of meals/day & & \\
Once & - & \\
Twice & 91 & 30.1 \\
Thrice & 151 & 50.0 \\
More than three times & 60 & 19.9 \\
& 100 & 302 \\
Reason for skipping meals & & \\
Lack of appetite & 30 & 9.9 \\
Insufficient money & 45 & 14.9 \\
To avoid over weight & 6 & 2.0 \\
No time & 10 & 3.3 \\
& 91 & 30.1 \\
Do you get satisfied at each & & \\
meal? & & \\
At times & 92 & 30.5 \\
Always & 78 & 25.8 \\
Often & 166 & 38.4 \\
Not at all & 16 & 5.3 \\
Who decides what the family & 352 & 100 \\
eats? & & \\
\hline
\end{tabular}

\begin{tabular}{lll}
\hline Variables & Frequency(F) & Percentage (\%) \\
\hline Father & 78 & 25.8 \\
Mother & 95 & 31.5 \\
Child/children & 123 & 40.7 \\
Relations & 6 & 2.0 \\
& 302 & 100 \\
Sources of water & & \\
Public Tap & 208 & 68.9 \\
Stream & 7 & 23.2 \\
Rain water & 34 & 11.2 \\
Pond & - & - \\
Others & 53 & 17.5 \\
& 302 & 120.8 \\
\hline
\end{tabular}

Table 3. Anthropometric indices of the pupils

\begin{tabular}{lll}
\hline & Frequency (n) & Percentage (\%) \\
\hline Height for age & & \\
Stunted & 121 & 40.1 \\
Normal & 166 & 55.0 \\
Above normal & 15 & 5.0 \\
Total & 302 & 100 \\
Weight for age & & \\
Underweight & 76 & 25.2 \\
Normal & 166 & 55.0 \\
Above normal & 60 & 19.9 \\
Total & 302 & 100 \\
Weight for height & & \\
Wasting & 121 & 40.1 \\
Normal & 136 & 45.0 \\
Above normal & 45 & 14.9 \\
Total & 302 & 100 \\
\hline
\end{tabular}

Table 3 showed the $40.1 \%$ of the subjects were stunted, $25.2 \%$ were underweight and $40.1 \%$ were wasted.

Table 4. Anthropometric indices of pupils based on different educational status of parents

\begin{tabular}{llllll}
\hline Anthropometry Status; & Primary (\%) & Secondary (\%) & Tertiary (\%) & No formal Education & Total (\%) \\
\hline Height for age & & & & & \\
Stunting & $22(48.9)$ & $23(31.5)$ & $73(42.7)$ & $3(23.1)$ & 121 \\
Normal & $20(44.4)$ & $45(61.6)$ & $91(53.2)$ & $10(76.9)$ & 166 \\
Above normal & $3(6.7)$ & $5(6.8)$ & $7(4.2)$ & - & 15 \\
Total & $45(100)$ & $73(100)$ & $171(100)$ & $13(100)$ & 302 \\
Weight for age & & & & & 76 \\
Underweight & $15(33.3)$ & $18(14.7)$ & $40(23.4)$ & $3(23.1)$ & 166 \\
Normal & $20(44.4)$ & $27(37.0)$ & $111(64.9)$ & $8(61.5)$ & 60 \\
Above normal & $10(22.2)$ & $28(38.4)$ & $20(11.7)$ & $2(15.4)$ & 302 \\
Total & $45(100)$ & $73(100)$ & $171(100)$ & $13(100)$ & 121 \\
Weight for height & & & & \\
Wasting & $15(33.3)$ & $28(38.4)$ & $75(43.9)$ & $3(23.1)$ & 136 \\
Normal & $22(48.39)$ & $23(31.5)$ & $81(47.4)$ & $10(76.9)$ & 45 \\
Above normal & $8(17.8)$ & $22(30.1)$ & $15(8.38)$ & - & 302 \\
Total & $45(100)$ & $73(100)$ & $171(100)$ & $13(100)$ & \\
\hline
\end{tabular}

Stunting: $x^{2}=7.0435$ at $6 . d f ; p>0.05$ No significant difference

Under weight: $\mathrm{x}^{2}=27.582$ at $6 . \mathrm{df} ; \mathrm{p}<0.05$ Significant difference

Wasting: $\mathrm{x}^{2}=23.103$ at $6 . \mathrm{df} ; \mathrm{p}<0.05$ Significant difference 
There was no significant difference $(\mathrm{P}>0.05)$ in the rate of stunting among the growth pattern of pupils based on different educational status of the parents, although stunting occurred more (48.9\%) among pupils whose parents had only primary education. Children their parents had tertiary education also had high record of stunting (42.7\%) while those that their parents had no formal education had recorded the least percentage of stunting $(23.1 \%)$. However, there were significant differences $(p<0.05)$ for wasting and underweight among the pupils whose parents' educational background differed. Parents with no formal education has a lowest proportion of children with wasting (23.1\%) than all other groups, while parents with tertiary education have the highest proportion of children with wasting (43.9\%) and pupils whose parents had only primary education recorded the most underweight (33.3\%).

Table 5. Anthropometric indices of pupils based on different occupational status of parents

\begin{tabular}{|c|c|c|c|c|c|}
\hline Anthropometry Status; & Civil servant (\%) & Trader (\%) & Farmer (\%) & Other & Total (\%) \\
\hline \multicolumn{6}{|l|}{ Height for age } \\
\hline Stunting & $60(45.8)$ & $18(51.4)$ & $3(23.1)$ & $40(32.5)$ & 121 \\
\hline Normal & $63(48.1)$ & $15(42.9)$ & $8(61.5)$ & $80(65)$ & 166 \\
\hline Above normal & $8(6.1)$ & $2(5.7)$ & $2(15.4)$ & $3(2.4)$ & 15 \\
\hline Total & $131(100)$ & $35(100)$ & $13(100)$ & $123(100)$ & 302 \\
\hline \multicolumn{6}{|l|}{ Weight for age } \\
\hline Underweight & $38(29)$ & $13(37.1)$ & $5(38.5)$ & $20(16.3)$ & 76 \\
\hline Normal & $80(61.1)$ & $12(34.3)$ & $5(38.5)$ & $68(55.3)$ & 166 \\
\hline Above normal & $13(9.9)$ & $10(28.6)$ & $3(23.1)$ & $35(28.5)$ & 60 \\
\hline Total & $131(100)$ & $35(100)$ & $13(100)$ & $123(100)$ & 302 \\
\hline \multicolumn{6}{|l|}{ Weight for height } \\
\hline Wasting & $66(50.4)$ & $13(37.1)$ & $5(38.5)$ & $37(30.1)$ & 121 \\
\hline Normal & $55(41.9)$ & $15(42.9)$ & $5(38.5)$ & $61(49.6)$ & 136 \\
\hline Above normal & $10(7.6)$ & $7(20.0)$ & $3(23.1)$ & $25(20.3)$ & 45 \\
\hline Total & $45(100)$ & $35(100)$ & $13(100)$ & $123(100)$ & 302 \\
\hline
\end{tabular}

Stunting: $\mathrm{x}^{2}=11.6973$ at $6 . \mathrm{df} ; \mathrm{p}>0.05$ No significant difference

Under weight: $\mathrm{x}^{2}=38.5373$ at $6 . \mathrm{df}: \mathrm{p}<0.05$ Significant difference

Wasting: $\mathrm{x}^{2}=16.9565$ at $6 . \mathrm{df}: \mathrm{p}<0.05$ Significant difference

Table 5 showed that the occupation of parents significantly $(\mathrm{p}<0.05)$ affected the anthropometric indices of weight for age and weight for height of their children. Higher rates of stunting (45.8\% and $51.4 \%$ respectively) were observed among the children of civil servants and those whose parents were traders than farmers $(23.1 \%)$ and others $(32.5 \%)$. Also, wasting was highest among children of civil servants $(50.4 \%)$, followed by children of farmers $(38.5 \%)$ and then, children of traders $(37.1 \%)$.

Table 6. Anthropometric indices of pupils based on different income level of parents

\begin{tabular}{lllll}
\hline $\begin{array}{l}\text { Anthropometry } \\
\text { Status }\end{array}$ & $\begin{array}{l}<\mathbf{2 0 , 0 0 0} \\
(\mathbf{\%})\end{array}$ & $\begin{array}{l}\mathbf{2 1 , 0 0 0}- \\
\mathbf{4 0 , 0 0 0}(\mathbf{\%})\end{array}$ & $\begin{array}{l}\mathbf{> 4 0 , 0 0 0} \\
(\mathbf{\%})\end{array}$ & $\begin{array}{l}\text { Total } \\
(\mathbf{\%})\end{array}$ \\
\hline $\begin{array}{l}\text { Height for age } \\
\text { Stunting }\end{array}$ & $39(43.3)$ & $73(39.7)$ & $9(33.3)$ & 121 \\
Normal & $45(50)$ & $103(56.0)$ & $18(66.7)$ & 166 \\
Above normal & $6(6.7)$ & $9(4.9)$ & - & 15 \\
Total & $90(100)$ & $184(100)$ & $27(100)$ & 302 \\
Weight for age & & & & \\
Underweight & $30(33.3)$ & $42(22.8)$ & $4(14.8)$ & 76 \\
Normal & $35(38.9)$ & $114(62.0)$ & $17(63.0)$ & 166 \\
Above normal & $26(28.9)$ & $27(14.7)$ & $7(25.9)$ & 60 \\
Total & $90(100)$ & $184(100)$ & $27(100)$ & 302 \\
Weight for height & & & & \\
Wasting & $43(47.8)$ & $74(40.2)$ & $4(14.8)$ & 121 \\
Normal & $28(31.1)$ & $85(45.7)$ & $23(85.2)$ & 136 \\
Above normal & $19(21.1)$ & $26(14.1)$ & - & 45 \\
Total & $90(100)$ & $184(100)$ & $27(100)$ & 302 \\
\hline
\end{tabular}

Stunting: $\mathrm{x}^{2}=2.5932$ at 4 d.f: $\mathrm{p}>0.05$ No significant difference Under weight: $\mathrm{x}^{2}=16.7622$ at 4 d.f: $\mathrm{p}<0.05$ Significant difference Wasting: $\mathrm{x}^{2}=22.8391$ at 6 d.f: $\mathrm{p}<0.05$ Significant difference
There was no significant difference $(p>0.05)$ in the rate of stunting of growth pattern of pupils base on different income level of parents, although pupils whose parents income $<20,000$ who were stunted where more than other groups $(43.3 \%)$. However, there were significant difference ( $p>0.05)$ in wasting and underweight among pupils whose parents income level differs. Wasting $(47.8 \%)$ is highest in children whose parents income level is $<20,000$.

\section{Discussion}

The aim of this study was to assess the Anthropometric Measurement of primary school children from different socio-economic classes in Owerri municipal council and to determine the anthropometric indices.

The data obtained showed that $(25.2 \%)$ of the subjects were underweight, (40.1\%) were stunted and as well wasted. This result is below what Glewwe ${ }^{[10]}$ found out that underweight and stunting were high among school age children (52.4\% and $35.1 \%$ respectively) in Malaysia.

The result gotten from the anthropometric status of subject base on occupational status of parents indicated that, the subjects whose parents was civil servant $(45.8 \%$ for stunting, 29\% for underweight and $50.4 \%$ for wasting) table 5 .

The dietary habits of the pupils (table 2) was discovered that the most reason why the subjects skip meals was insufficient fund (14.9\%) Only $38.4 \%$ of the subjects get satisfied at each meal. The effect of the income of the 
parents on the height and weight of the subjects was assessed. There was significant difference $(p>0.05)$ in the growth pattern of the subjects as determined by the anthropometric measures of subjects of the parents of higher income as against subjects of the low income parents. Research ${ }^{[11,12]}$ reported that children of higher class families from the University of Port Harcourt in Nigeria were taller and heavier than those of traders. In another survey ${ }^{[10]}$, it was reported that the elite children were heavier and taller than their counter parts attending public primary school in the city or rural areas. Food intake of children of higher socio-economic groups were higher and of better quality than that of other groups. Hammil et al., ${ }^{[11]}$ in the study done in America, showed children whose parents were in professional and managerial classes were $3 \mathrm{~cm}$ taller than children whose fathers were labourers. Similar findings were also made in another survey ${ }^{[11-13]}$. This difference might be related to the fact that parents with high income range N21,000 - N40,000 can afford more nutritious food for their children than those with low income range $\mathrm{N} 20,000$.

The effect of family type on the heights and weights of subjects were determined from different classes, monogamous and polygamous family. Analysis of the result showed that a significant difference $(p<0.05)$ existed between the height and weights of children with smaller family size (monogamous family) and those with large family size (polygamous family). Couples with many children beyond their feeding capacity lacked the ability to take care of their nutritional requirements which in turn affects their nutritional status.

\section{Conclusion}

The result of this study showed that there is need for Nutritional programs to improve the diet of primary school children which include supplementary feeding arrangements. It has been stated that supplementary feeding when planned and operated properly can result in the improvement of the nutritional status of children. School meals should be considered as a suitable vehicle for adequate dietary intake to improve the nutritional status of the children. I therefore recommend that government should support and sponsor free school lunch programs in all primary schools. Similarly, proprietors of these primary schools can organize seminar for teachers to create awareness on the need of adequate nutrition. This will enable the teachers to identify malnourished children and help advice their parents appropriately.

\section{References}

[1] Jellife D.B. and Stanfield (1989). Diseases of children in the Sub-tropics and tropics. ELBS and Edward Arnold Ltd.99

[2] Jeffrey Baron (2006). The assessment of the nutritional status of the community. WHO, Geneva. 50-76.

[3] Whitney, E. and Rolfes, S.R. (2008). Understanding Nutrition. Eleventh Edition. United States: International Student Edition. WADSWORTH CENGAGE LEARNING.

[4] Srilakshmi, B. (2005); Dietetics. Revised Fifth Edition. New Age International Publishers. New Delhi.

[5] Srilakshmi, B. (2008); Nutrition Science. Third Edition. New Age International Publishers. New Delhi.

[6] Wilson E.D. fisher K.H. and Garcia, P.A. (1992). Principles of nutrition, $4^{\text {th }}$ edition John Wiley and sons inc. Page 410.

[7] Nduba, V.I. (1998). Anthropometric indices of primary school children from two socio-economic status A.M.B.B.S. project submitted to University of Nigeria Nsukka. (Unpublished) 34-36.

[8] Nnanyelugo, D.O. (1980). Nutritional status of children in Imo State journal of nutrition. Science. 1.20-26

[9] Nwosu O.I. C.1, Nnam N.N., Ibeziako N and Maduforo A.N.(2014). Development and Nutritional Evaluation of Infant Complementary Food from Maize (Zea Mays), Soybean (Glycine Max) and Moringa Oleifera Leaves International Journal of Nutrition and Food Sciences 2014; 3(4): 290-299

[10] Glewwe, P. (2002). School and skills in developing countries: education policies and socio-economic outcomes, journal of economics literature, $40.36-8$

[11] Hammil, A.H. John, O.A and Hart H.A. (1987). The height and weight of children: socio-economic status Washington D.C. United States U.S. Dept of health Edu and wel. Publ. 73.1601 .

[12] Akinlosutu, R.A and Hussain M.A. (1985). The usefulness of height at First year of schooling as an index of nutritional status of a community Nig. Jour of Nutr. Sci 6.131-139

[13] Ladition, A.A. (1998). Nutrition and physical growth in childhood. Nigeria journal of nutrition. Sci. 4.5-10 